\title{
Penyuluhan Cara Cuci Tangan Bagi Pengunjung Rumah Sakit Universitas Mataram
}

\author{
Isna Kusuma Nintyastuti*, Titi Pambudi Karuniawaty, \\ Mohammad Rizki, Yunita Hapsari
}

Fakultas Kedokteran Universitas Mataram/Rumah Sakit Universitas Mataram, Mataram, Indonesia

\section{Article history}

Received: 30-12-2020

Revised: 25-03-2021

Accepted: 15-07-2021

*Corresponding Author: Isna Kusuma Nintyastuti, Fakultas Kedokteran Universitas Mataram/Rumah Sakit Universitas Mataram, Mataram, Indonesia;

Email:

isnasuninto@unram.ac.id
Abstract: Washing hands with soap for 20 seconds is an effective prevention effort against various infectious diseases. In the COVID-19 pandemic, mastery of good and correct hand washing by the wider community plays a major role in efforts to prevent disease transmission. Mataram University Hospital which is a hospital that serves as a vehicle for education is the right place to apply knowledge and disseminate knowledge to the wider community, especially hospital visitors about how to wash hands in order to prevent the spread of COVID-19. Therefore, we do community service in the form of counseling on how to wash hands for visitors to the Mataram University Hospital. This service aims to increase the knowledge of visitors to the Mataram University Hospital on how to wash their hands. Counseling is carried out in the visitor's waiting room, both at registration, pharmacy and outpatient. Young doctors who are conducting education are also involved in this activity. Counseling is carried out by inviting the demonstrators to directly practice hand washing steps according to World Health Organization (WHO) standards. During the period from August to October, there were 7 counseling sessions and hand washing practices for visitors to the Mataram University Hospital. The media used in the counseling were banners with pictures of hand washing steps and hand sanitizers for direct practice by visitors. The involvement of young doctors and good coordination with the education and health promotion sectors of the hospital support this activity.

Keywords: counseling; washing hands; visitors; hospitals; covid-19

Abstrak: Cuci tangan menggunakan sabun selama 20 detik merupakan upaya pencegahan yang efektif terhadap berbagai penyakit menular. Pada pandemi COVID-19, penguasaan cara cuci tangan yang baik dan benar oleh masyarakat luas sangat berperan besar dalam upaya pencegahan penularan penyakit. Rumah Sakit Universitas Mataram yang merupakan rumah sakit yang menjadi wahana pendidikan merupakan tempat yang tepat untuk menerapkan pengetahuan dan menyebarluaskan ilmu pengetahuan pada masyarakat luas, terutama pengunjung rumah sakit tentang cara cuci tangan dalam rangka pencegahan penyebaran COVID-19. Oleh karena itu kami lakukan pengabdian masyarakat berupa penyuluhan cara cuci tangan bagi pengunjung Rumah Sakit Universitas Mataram. Pengabdian ini bertujuan untuk meningkatkan pengetahuan para pengunjung Rumah Sakit Universitas Mataram tentang cara mencuci tangan. Penyuluhan dilakukan di ruang tunggu pengunjung, baik di pendaftaran, farmasi maupun rawat jalan. Dokter muda yang sedang melakukan pendidikan juga dilibatkan dalam kegiatan ini. Penyuluhan dilakukan dengan mengajak pengunjuk mempraktekkan langsung langkah-langkah cuci tangan sesuai standar World Health Organization (WHO). Selama periode Agustus sampai dengan Oktober telah dilakukan 7 kali penyuluhan dan praktek cara cuci tangan bagi pengunjung Rumah Sakit Universitas Mataram. Media yang digunakan dalam penyuluhan adalah banner gambar langkah-langkah cuci tangan dan hand sanitizer untuk praktek langsung 
oleh pengunjung. Keterlibatan dokter muda dan koordinasi yang baik dengan bidang pendidikan dan bidang promosi kesehatan rumah sakit mendukung berlangsungnya kegiatan ini.

Kata Kunci: penyuluhan; cuci tangan; pengunjung; rumah sakit; covid-19

\section{PENDAHULUAN}

Pada akhir 2019 telah terjadi pandemi COVID-19 di dunia. Menurut World Health Organization (WHO), salah satu upaya penting dalam pencegahan penyebaran penyakit adalah dengan menccuci tangan. Mencuci tangan dengan langkah dan waktu yang tepat dapat menghilangkan organisme patogen pada permukaan tubuh. Langkah-langkah mencuci tangan yang direkomendasikan adalah 6 langkah cuci tangan menggunakan air dan sabun atau menggunakan alkohol (World Health Organization, 2020).

Tingkat pengetahuan masyarakat tentang cara cuci tangan yang tepat masih cukup rendah (Lestari, 2019). Upaya penyuluhan dan sosialisasi mencuci tangan telah banyak dilakukan dan dapat meningkatkan pengetahuan masyarakat tentang cuci tangan (Maruni Wiwin Diarti, 2020). Meskipun demikian, upaya sosialisasi cuci tangan tetap harus dilakukan secara terus menerus, terutama di masa pandemi.

Rumah Sakit Universitas Mataram (RS Unram) merupakan salah satu rumah sakit di wilayah Kota Mataram yang menjadi wahana pendidikan bagi mahasiswa kedokteran tingkat profesi. Salah satu misi dari rumah sakit tersebut adalah memberikan pelayanan dan juga sekaligus pendidikan yang berkualitas sesuai kebutuhan masyarakat (Rumah Sakit Universitas Mataram, 2019). Oleh karena itu, rumah sakit selalu melakukan usaha-usaha promosi kesehatan termasuk upaya pencegahan penyakit menular. Pada masa pandemi COVID-19, Rumah Sakit Universitas Mataram merupakan salah satu rumah sakit yang merawat pasien COVID-19 dan memiliki fasilitas pemeriksaan laboratorium untuk penegakan diagnosisnya. Sebagai salah satu usaha komprehensif upaya penanganan COVID-19, adalah melakukan pendekatan penangan dari aspek kuratif dan promotif.

WHO telah memandatkan petugas kesehatan untuk selalu melakukan edukasi cuci tangan kepada masyarakat dalam upaya pencegahan penyebaran penyakit (Singh, 2020). Kurangnya pengetahuan masyarakat dan dalam usaha menjalankan mandat tersebut menjadi latar belakang kami luntuk melakukan pengabdian masyarakat berupa penyuluhan cara cuci tangan bagi pengunjung Rumah Sakit Universitas Mataram. Pengabdian ini bertujuan untuk meningkatkan pengetahuan para pengunjung RS Unram tentang cara mencuci tangan.

\section{METODE}

Kegiatan ini ini berupa penyuluhan tentang cara atau langkah cuci tangan yang benar sesuai rekomendasi WHO. Media yang digunakan dalam kegiatan ini adalah media visual berupa banner berisi gambar langkah-langkah cuci tangan, media auditoris berupa ceramah pemaparan cara cuci tangan, demonstrasi dan praktik langsung oleh pengunjung. Kegiatan ini melibatkan dokter muda atau mahasiswa tingkat profesi Fakultas Kedokteran Universitas Mataram yang sedang melakukan pendidikan di RS Unram. Lokasi dan sasaran penyuluhan adalah pengunjung di ruang tunggu pendaftaran, ruang tunggu farmasi, ruang tunggu poliklinik lantai 1 dan lantai 2. 


\section{HASIL DAN PEMBAHASAN}

Selama periode Agustus sampai dengan Oktober telah dilakukan 7 kali penyuluhan dan praktek cara cuci tangan bagi pengunjung Rumah Sakit Universitas Mataram. Jumlah pengunjung yang berpartisipasi adalah 73. Gambar 1 memaparkan tanggal kegiatan dan jumlah peserta pada setiap kegiatannya.

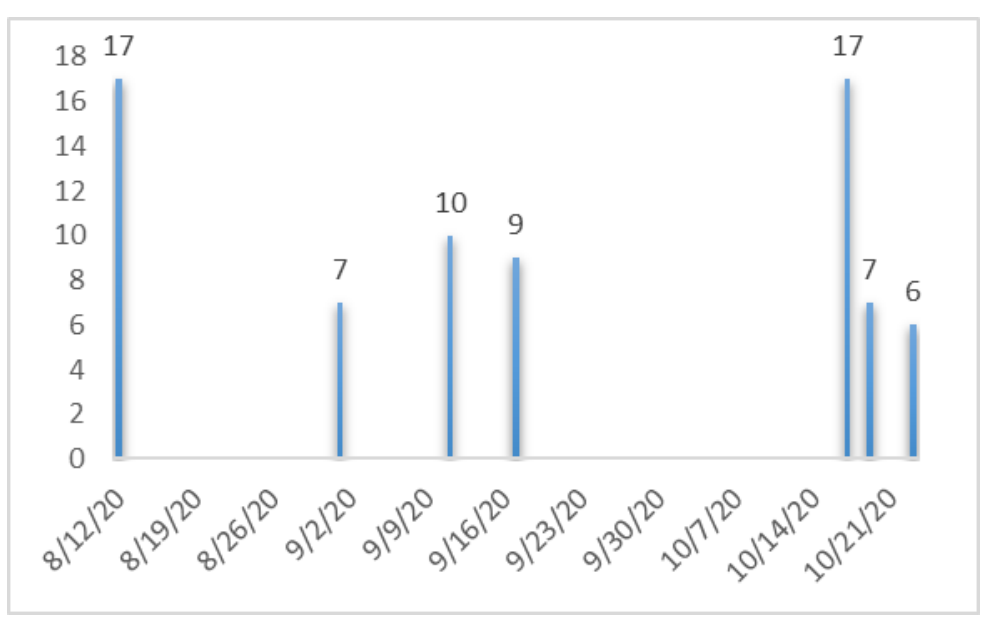

Gambar 1. Diagram waktu pelaksanaan kegiatan dan jumlah peserta

Pada gambar 1 dapat dilihat bahwa kegiatan berlangsung setidaknya setiap 1-3 minggu sekali. Jumlah pengunjung yang berpartisipasi bervariasi sesuai jumlah pengunjung yang sedang menunggu untuk dilayani.

Pelaksanaan kegiatan penyuluhan dilakukan oleh dokter muda dibimbing oleh dosen pendidik klinik. Kegiatan berupa ceramah, demonstrasi dan praktik langsung memudahkan retensi pengetahuan yang ditransfer. Antusiasme pengunjung dalam mengikuti pemaparan dan menjalankan praktek langsung cukup baik.

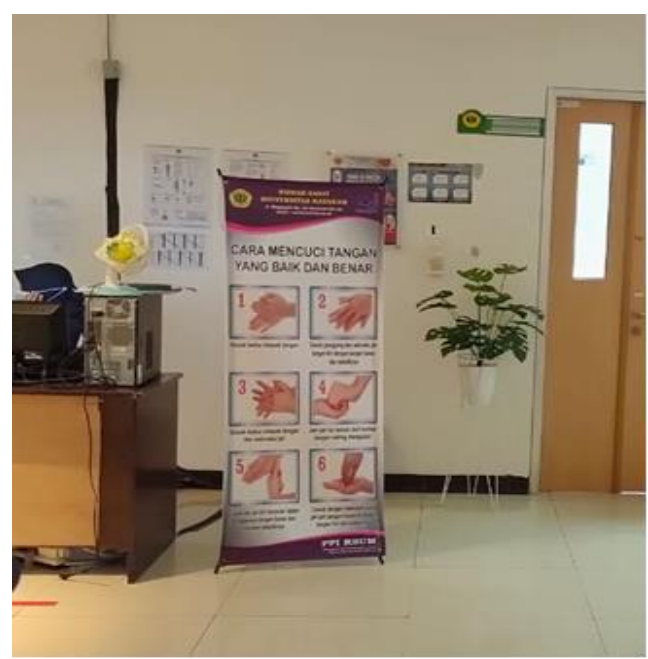

Gambar 2. Media visual gambar

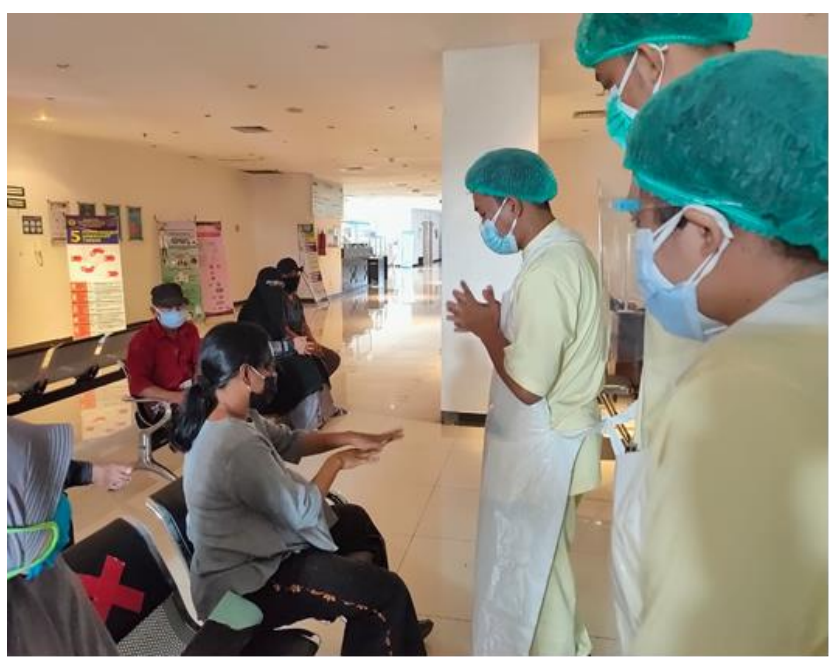

Gambar 3. Praktik langsung oleh pengunjung

Penyuluhan yang dilakukan menggunakan media yang beragam. Media visual yang digunakan dalam penyuluhan adalah banner gambar langkah-langkah cuci tangan dan demonstrasi cara cuci tangan. Media visual banner gambar memudahkan peserta untuk mengulang dan melakukan sendiri 
cara cuci tangan, sehingga diharapkan retensi pengetahuan peserta lebih baik. Media auditoris yang digunakan adalah ceramah dengan suara yang lantang sehingga mudah didengar dan memberikan input pengetahuan bahkan untuk paengunjung dengan gangguan penglihatan. Hand sanitizer digunakan untuk praktek langsung oleh pengunjung. Penggunaan media informasi yang beragam memberikan kemungkinan yang lebih besar untuk terjadinya retensi pengetahuan bagi pengunjung yang menjadi peserta penyuluhan.

Penyuluhan telah dilakukan di seluruh area tunggu yang direncanakan, yaitu ruang tunggu pendaftaran, farmasi dan poliklinik lantai 1 dan 2. Pelaksanaan penyuluhan di hampir seluruh ruang tunggu rawat jalan meningkatkan kesempatan pengunjung untuk turut mendengar dan mengikuti penyuluhan.

Secara umum kegiatan telah berlangsung dengan baik, namun demikian masih terdapat hambatan dalam pelaksanaannya yaitu antara lain adalah waktu tunggu yang singkat pada pelayanan sehingga jumlah pasien di ruang tunggu cepat silih berganti. Hal tersebut membuat beberapa pengunjung tidak dapat mengikuti penyuluhan dengan lengkap

\section{Kesimpulan}

1. Telah dilakukan penyuluhan cara cuci tangan pada pengunjung RS Unram dengan media informasi visual, auditoris dan praktek langsung.

2. Antusiasme pengunjung untuk melakukan praktek cuci tangan cukup baik.

3. Keterlibatan dokter muda dan koordinasi yang baik dengan bidang pendidikan dan bidang promosi kesehatan rumah sakit mendukung berlangsungnya kegiatan ini.

\section{Saran}

1. Perlu dilakukan pengukuran peningkatan keterampilan cuci tangan secara lebih objektif setelah pelaksanaan penyuluhan.

2. Kegiatan penyuluhan cuci tangan harus dilanjutkan agar masyarakat makin paham tentang upaya pencegahan COVID-19 yang meliputi cuci tangan menggunakan sabun, memakai masker dan menjaga jarak untuk menghentikan penyebaran COVID-19 di Indonesia khususnya di wilayah Nusa Tenggara Barat.

\section{Ucapan Terima Kasih}

Kami ucapkan terimakasih kepada seluruh jajajaran RS Unram yang telah mendukung dan menjadi lokasi kegiatan ini. Terimakasih juga kami sampaikan untuk Tim Koordinasi Pendidikan RS Unram, Program Profesi Dokter Fakultas Kedokteran Universitas Mataram dan seluruh Dokter muda yang terlibat dalam kegiatan ini.

\section{DAFTAR PUSTAKA}

Rumah Sakit Universitas Mataram, 2019. Rumah Sakit Universitas Mataram. [Online] Available at: https://rs.unram.ac.id [Accessed 3011 2020].

Lestari, A. O. A. W., 2019. Hubungan Pengetahuan Dan Sikap Terhadap Perilaku Cuci Tangan Pada Masyarakat Kelurahan Pegirian. Jurnal Promkes: The Indonesian Journal of Health Promotion and Health Education, 7(1), pp. 1-11.

Singh, P. K., 2020. Promote hand hygiene to save lives and combat COVID-19. [Online] Available at: https://www.who.int/southeastasia/news/detail/04-05-2020-promote-hand-hygiene-to-savelives-and-combat-covid-19 [Accessed 30 November 2020]. 
World Health Organization, 2020. Infection prevention and control during health care when coronavirus disease (COVID-19) is suspected or confirmed, Geneva: World Health Organization.

Maruni Wiwin Diarti, Y. J. A. D., 2020. Edukasi Masyarakat Melalui Aktivitas Relawan Non Medis Dalam Memutus Rantai Penyebaran Covid-19 Di Lingkungan Cakranegara Utara. Jurnal Pengabdian Masyarakat Sasambo, 2(1), pp. 150-155. 